\title{
Queimadura por eletrocautério, integridade tissular prejudicada e assistência de enfermagem: relato de caso
}

\author{
Electrocauterium burns, impaired tissue integrity and nursing care: case report \\ Quemaduras por electrocauterio, deterioro de la integridad de los tejidos y atención de \\ enfermería: reporte de caso
}

Ana Caroliny da Silva ${ }^{1 *}$, Lais Lara Silva Xavier ${ }^{1}$, Thainara Lorraine Costa e Silva Pereira ${ }^{1}$, Mykaella Cristina Araújo Margarida², Gabriela Maria Lara de Paulo ${ }^{1}$, Erilane Soares da Silva ${ }^{1}$, Isabela Leal Moreira $^{1}$, Suzy Aparecida Luiz da Silva ${ }^{1}$, Thais Vilela de Souza ${ }^{2}$, Lorena Morena Rosa Melchior ${ }^{2}$.

\section{RESUMO}

Objetivo: Relatar um caso de cuidados de enfermagem prestados a uma paciente com integridade tissular prejudicada decorrente de queimadura durante procedimento de cauterização de lesões anogenitais por Papiloma Vírus Humano. Detalhamento do caso: Trata-se de um estudo descritivo do tipo relato de caso que partiu da vivência de enfermeiros sobre os cuidados dispensados a uma paciente internada em hospital público de grande porte, referência em tratamento de pacientes queimados. Paciente L.A.A, sexo feminino, 34 anos de idade, solteira, lesão em área perineal compatível com queimadura de II e III grau que se estendia desde a vagina até o ânus causada por agente térmico/eletricidade (chama direta + choque elétrico). Considerações finais: Os cuidados de enfermagem a paciente deste estudo de caso visavam, sobretudo, a promoção e recuperação da integridade da pele. O enfermeiro exerce um papel fundamental no processo de cicatrização da ferida e prevenção da infecção, que é uma das causas de morte entre os pacientes queimados.

Palavras-chave: Queimaduras, Cauterização, Cuidados de enfermagem, Terminologia padronizada em enfermagem, Cicatrização.

\section{ABSTRACT}

Objective: To report a case of medical care provided to a patient with tissue integrity damaged by burns during the cauterization procedure of anogenital lesions caused by Human Papillomavirus. Case details: This is a descriptive case report study that started from the experience of nurses regarding the care of a patient admitted to a large public hospital, a reference for the treatment of burn patients. Patient L.A.A., female, 34 years old, single, lesion in the perineal region compatible with grade II and III burns that extend to the vagina or anus caused by a thermal agent / electrode (flame + direct electric shock). Final considerations: The patient care in this case study aimed, mainly, to promote and restore the integrity of the skin. The nurse plays a fundamental role not in the wound healing process and infection prevention, which is one of the causes of death in burn patients.

Keywords: Burns, Cautery, Nursing care, Standardized nursing terminology, Wound healing.

\section{RESUMEN}

Objetivo: Informar un caso de atención médica brindada a un paciente con integridad tisular dañada por quemaduras durante el procedimiento de cauterización de lesiones anogenitales causadas por Virus del Papiloma Humano. Detalles de caso: Se trata de un estudio descriptivo de relato de caso que parte de la

1 Secretaria de Estado de Saúde de Goiás (SES-GO), Goiânia - GO. *E-mail: ana.caroliny300@hotmail.com

${ }^{2}$ Universidade Federal de Goiás (UFG), Goiânia - GO. 
experiencia de enfermeras en el cuidado de un paciente ingresado en un gran hospital público, referente para el tratamiento de pacientes quemados. Paciente L.A.A., mujer, 34 años, única, lesión en la región perineal compatible con quemaduras grado II y III que se extienden a la vagina $\mathrm{o}$ al ano provocadas por un agente térmico / electrodo (Ilama + descarga eléctrica directa). Consideraciones finales: La atención al paciente en este estudio de caso tuvo como objetivo, principalmente, promover y restaurar la integridad de la piel. La enfermera juega un papel fundamental no en el proceso de cicatrización de heridas y prevención de infecciones, que es una de las causas de muerte en pacientes quemados.

Palabras clave: Quemaduras, Cauterización, Atención de enfermería, Terminología normalizada de enfermería, Cicatrización de heridas.

\section{INTRODUÇÃO}

As queimaduras são lesões provocadas pelo contato direto com algum elemento com capacidade de gerar alta fonte de calor, que ocasionam danificação aos tecidos e morte celular. As lesões podem ser classificadas conforme sua profundidade em primeiro, segundo (superficial ou profunda) ou terceiro grau. As lesões de primeiro grau são superficiais, com comprometimento apenas da epiderme. As de segundo grau superficiais comprometem a epiderme e parte da derme, se caracterizam pela formação de edema e flictenas. As de segundo grau profundas atingem a epiderme e toda a derme, costumam ser esbranquiçadas. As de terceiro grau acarretam a destruição de toda epiderme e derme, podendo ainda comprometer o tecido subcutâneo e estruturas mais profundas (GARCIA-ESPINOZA JA, et al., 2017; SAAVEDRA PAE, et al., 2019).

Essas lesões podem ser ocasionadas por diferentes agentes agressores tais como térmicos, químicos, elétricos ou radioativos. Dentre as possíveis causas de queimaduras, existem as ocasionadas durante procedimentos cirúrgicos, que podem estar associadas a utilização do eletrocautério, placa de bisturi e a utilização de soluções de preparação da pele de pacientes contendo álcool e compostos voláteis. Estudos apontam alguns danos, como tais lesões, em decorrência de procedimentos cirúrgicos, estando relacionados a falhas de segurança durante os processos de assistência (MEHTA SP, et al., 2013; TIAN H, et al., 2018).

A assistência de enfermagem ao paciente com lesão é multifacetada e requer um preparo da equipe, em especial o enfermeiro, o qual é responsável por determinar as necessidades do paciente, confeccionar o plano de cuidado, supervisionar sua execução e monitorar sua efetividade (SECUNDO CO, et al., 2019).

Para que esse cuidado ocorra de modo equânime, destaca-se a Resolução no 358/2009 que dispõe sobre a Sistematização da Assistência de Enfermagem (SAE) e a implementação do Processo de Enfermagem (PE) em todos os ambientes públicos e privados. O PE engloba cinco etapas: coleta de dados, diagnóstico de enfermagem, planejamento, implementação e avaliação. O estabelecimento do Diagnóstico de Enfermagem (DE) permite planejar os melhores cuidados, de acordo com a necessidade real do paciente, de forma a alcançar resultados pelos quais o enfermeiro é responsável (CONSELHO FEDERAL DE ENFERMAGEM (COFEN), 2009).

A North American Nursing Diagnosis Association International (NANDA-I) formalizou uma metodologia de classificação dos DE, que tem por finalidade descrever e desenvolver uma fundamentação com embasamento científico, encorajando enfermeiros no mundo todo a buscarem uma prática independente. Portanto, a NANDA-I preconiza uma maneira de classificar e categorizar áreas de preocupação para a profissão (MELO UG, et al., 2019; HERDMAN H, et al., 2021).

O diagnóstico de Integridade Tissular Prejudicada geralmente é elencado como prioritário nos casos de pacientes vítimas de queimaduras de segundo grau profunda e terceiro grau, podendo ser conceituado como prejuízo às membranas, mucosas, córnea, tecidos subcutâneos, fáscia muscular, músculo, tendão e osso. Fatores relacionados ao paciente como idade, estado nutricional, agente etiológico e características da lesão contribuem para construção de um plano individual que objetive melhorar o prognóstico e a qualidade de vida desse paciente (HERDMAN H, et al., 2021).

O interesse em abordar o assunto surgiu durante assistência a uma paciente vítima de queimadura térmica durante realização de procedimento cauterização de lesão anogenital, onde percebeu-se a importância de 
uma atuação baseada em evidências e a complexidade na assistência de enfermagem a estes pacientes. $O$ objetivo do artigo foi relatar um caso de cuidados de enfermagem prestados a uma paciente com integridade tissular prejudicada decorrente de queimadura durante procedimento de cauterização de lesões anogenitais por Papiloma Vírus Humano (HPV).

\section{DETALHAMENTO DO CASO}

A pesquisa seguiu a Resolução 466/2012 do Conselho Nacional de Saúde que regulamenta pesquisas que envolvem seres humanos. Esse estudo foi aprovado pelo comitê de ética em pesquisa Leide das Neves Ferreira, sob número de parecer: 4.584.349 e CAAE de número 43431721.2.0000.5082. Sendo assim, a paciente foi orientada sobre a proposta do relato, atestando sua ciência e concordância por meio da assinatura do Termo de Consentimento Livre Esclarecido autorizando a divulgação do caso e uso da imagem.

Paciente L.A.A, sexo feminino, 34 anos de idade, solteira, auxiliar de serviços gerais, ensino fundamental incompleto, primigesta e primípara, nega comorbidades, etilismo e/ou tabagismo. Relata que no dia 08/05/2020 foi submetida, em seu município de residência, ao tratamento de cauterização devido às lesões genitais (do tipo verrugas) causadas pelo Papiloma Vírus Humano (HPV) mais especificamente na região anogenital. Refere que durante este procedimento, sofreu queimadura acidental e iatrogênica, uma vez que a pele foi preparada para o procedimento com antisséptico alcoólico e na presença do uso do eletrocautério, provocou combustão e chama (Figura 1).

Figura 1 - Lesão compatível com queimadura, após primeiro desbridamento.

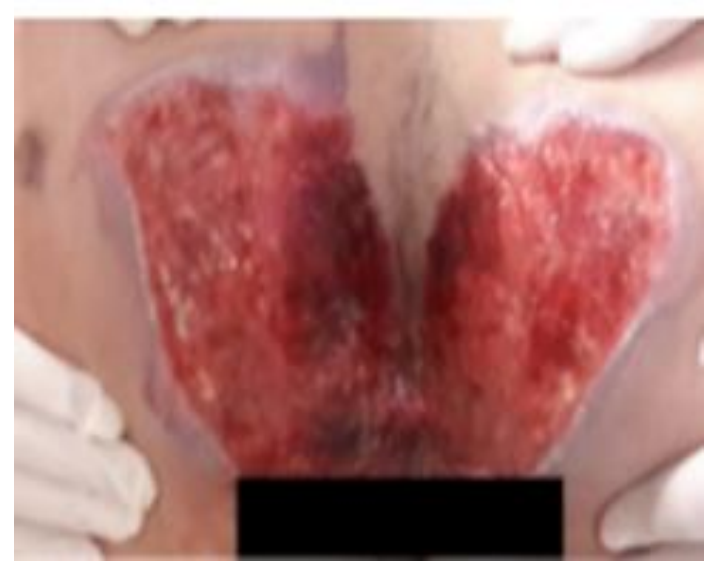

Fonte: Silva AC, et al., 2021.

A paciente foi então encaminhada no dia posterior para um hospital público de grande porte referência em tratamento de pacientes queimados na região centro-oeste do país. Durante a admissão, em 09/05/2020, identificou-se uma lesão em área perineal compatível com queimadura de II e III grau que se estendia desde a vagina até o ânus causada por agente térmico/eletricidade (chama direta + choque elétrico) (Figura 1). Constatou-se pela escala de Lund Browder que a Superfície Corporal Queimada (SCQ) era de 9\%. No mesmo dia da admissão, a paciente foi conduzida ao centro cirúrgico para realização do primeiro desbridamento cirúrgico e, em seguida, encaminhada para o leito de enfermaria.

Na realização do primeiro curativo, em 10/05/2020, utilizou-se inicialmente na cobertura primária pomada de alginato de cálcio e sódio com a intenção de auxiliar na remoção de tecido inviável por meio do debridamento autolítico seletivo. Devido à presença de fibrina na lesão, fez-se necessário ainda nos dias 14/05, 19/05, 24/05 e 28/05 a realização de outros desbridamentos cirúrgicos. Na última intervenção cirúrgica, foi coletado fragmento de tecido, enviado para análise por meio de cultura e identificação de microrganismos colonizadores da lesão. Foram então detectados Enterococcus Faecalis e Acinetobacter, fato que exigiu a instituição de precauções de contato, uma vez que, um dos agentes em questão se tratava de microrganismo multidroga-resistente. 
Durante o período de hospitalização da paciente, o diagnóstico de enfermagem identificado como prioritário de acordo com a taxonomia NANDA-I (International Nursing Diagnoses), foi Integridade tissular prejudicada relacionado à procedimento cirúrgico, evidenciado por dano tecidual, dor aguda e tecido destruído (HERDMAN H, et al., 2021). Portanto, o plano terapêutico para internação buscou favorecer o processo de cicatrização com execução diária do curativo, sendo que as características da lesão eram analisadas pelos enfermeiros com o objetivo de escolher a melhor cobertura, produtos e conduta mais apropriada. Foi indicado também cateterismo vesical de demora com a finalidade de controle de umidade na lesão.

No dia 05/06/2020 a paciente foi submetida a procedimento de enxertia de pele, ocasião em que se optou por um tratamento tópico no curativo com gazes de rayon secas e ocluído com compressas, objetivando manter a área seca e protegida para facilitar o processo de aderência da área enxertada. Após três dias de realização o enxerto da região perianal bilateral, no dia 08/06/2020, realizou abertura e detectou-se adequada adesão do tecido enxertado (Figura 2).

Figura 2 - Lesão após enxertia.

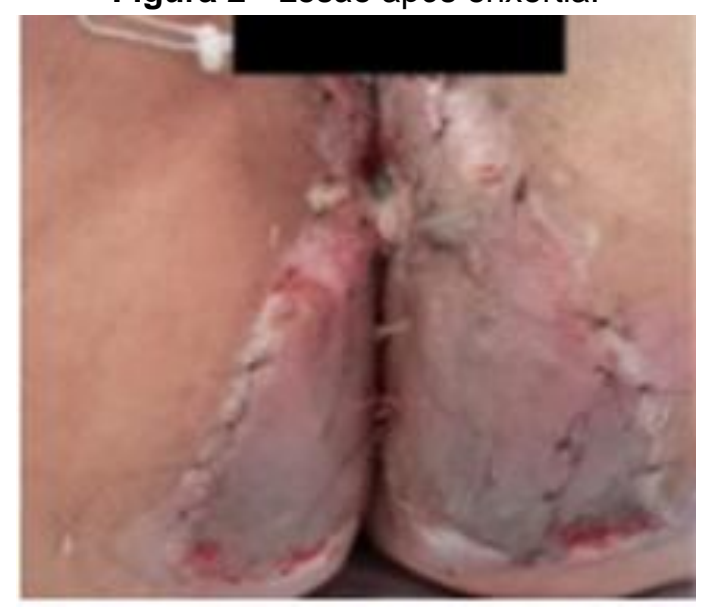

Fonte: Silva AC, et al., 2021.

No dia 10/06/2020 depois de um mês e um dia de internação, ocorreu a alta hospitalar, com retirada dos dispositivos invasivos, orientação de enfermagem de cuidados com área enxertada em domicílio e retorno ambulatorial agendado. Após quatro consultas ambulatoriais, no dia 21/01/2021 paciente recebeu alta ambulatorial, com total epitelização de área enxertada.

\section{DISCUSSÃO}

É amplamente conhecido que o Papiloma Vírus Humano (HPV) representa importância epidemiológica e grande impacto na saúde pública uma vez que é a doença sexualmente transmissível mais prevalente no mundo, tem potencial para promover processo oncogênico para o câncer de colo uterino e possibilita a ocorrência de verrugas anogenitais, como ocorrido com a paciente deste relato de caso (MINISTÉRIO DA SAÚDE, 2020; CARVALHO NS, et al., 2021).

De igual modo, a paciente em questão foi submetida ao tratamento de eletrocauterização, procedimento preconizado pelo Ministério da Saúde e oferecido pelo Sistema Único de Saúde (SUS), para lesões por HPV do tipo verrugas anogenitais. Este procedimento exige equipamento específico, anestesia local e seus resultados dependem da experiência do operador, além do fato de que o uso inadequado da técnica ter potencial para resultar em cicatrizes desfigurantes e ainda ocasionar estenose ou fístulas tubulares, de forma mais rara (MINISTÉRIO DA SAÚDE, 2020).

Não foram encontrados relatos na literatura de casos análogos ao caso clínico aqui apresentado. Entretanto, há descrições sobre queimaduras acidentais com placas de bisturi (BISINOTTO FMB, et al., 2017) que semelhantemente tem o mesmo princípio do ocorrido neste caso, causada por agente térmico/eletricidade (chama direta + choque elétrico). 
$\mathrm{Na}$ literatura existem várias discussões sobre as coberturas utilizadas para tratamento de lesão ocasionada por queimadura. A cobertura utilizada neste caso estudado foi a composta de alginato de cálcio e sódio. Em estudo experimental in vivo, foi observada cicatrização mais rápida por completa reepitelização em menor tempo, benefícios atribuídos ao cálcio que é liberado no leito da ferida (STOJKOVSKA J, et al., 2018). Estudo observacional descreveu excelentes resultados com a utilização desta cobertura em relação à progressão da ferida, sendo o único ponto negativo o relato de dor no local (GOUVÊA PDP, et al., 2020).

Mesmo assim, há vários produtos no mercado farmacêutico atribuídos ao cuidado com feridas provocadas por queimaduras em suas diferentes fases, no entanto, a utilização de qualquer item no tratamento destas lesões deve seguir um protocolo exigente, com o fim de identificar a real contribuição para o processo de cicatrização (NUNES RS e LOPES KKM, 2018).

No tratamento da lesão proveniente da queimadura também pode se fazer necessário o desbridamento cirúrgico, como ocorrido neste caso. Remover os tecidos desvitalizados é preciso pois, qualquer quantidade de tecido necrótico facilita a promoção de um proAcesso infeccioso por ser um meio propício para infecção em que são fornecidos nutrientes para bactérias anaeróbias, o que também reduz a biodisponibilidade de oxigênio para os tecidos. Dessa maneira, percebe-se que a condução do caso, mais uma vez, seguiu abordagens previstas pelas evidências disponíveis (CHAVES SCS, et al., 2013).

Além do desbridamento autolítico e cirúrgico, pode-se lançar mão da enxertia de pele. Enxertos de pele são transplantes cutâneos, retirados de um local e transferidos para outro. As indicações para realização do procedimento incluem feridas extensas e de difícil cicatrização, como queimaduras, abrasões, lesões traumáticas e deformidades congênitas que se submeteram a correções cirúrgicas (ALVES LM, et al., 2009; SARMENTO BS, et al., 2018).

A realização do enxerto de pele demanda cuidados específicos. No período pós-operatório deve-se assegurar a imobilização do local enxertado para evitar descolamento do enxerto e consequente não adesão. A literatura recomenda a abertura do curativo no terceiro ao quinto dia de pós-operatório, evitando molhar o curativo durante este período. Para a realização do curativo da área enxertada, recomenda-se a utilização de gaze antiaderente com curativo primário e ocluído com compressas e ataduras como cobertura secundária, visando a absorção do exsudato (UNAL S, et al., 2005; SARMENTO BS, et al., 2018).

Durante os primeiros 3 a 6 meses após a enxertia de pele, podem ocorrer mudanças notáveis, como a elevação e endurecimento das áreas recém-cicatrizadas. É recomendado a utilização de malha compressiva, visto que a pressão acelera a maturação da cicatriz e minimiza a formação de cicatriz hipertrófica (BORGES FS, 2010).

Segundo a resolução COFEN oㅜ 0567/2018, o enfermeiro é autorizado a avaliar, prescrever e executar curativos em todos os tipos de feridas em pacientes sob seus cuidados, além de coordenar e supervisionar a equipe de enfermagem na prevenção e cuidado de pessoas com feridas. Porém, o atendimento ao paciente queimado é tarefa delicada e específica, requer que o enfermeiro que o assiste tenha pensamento crítico que propicie uma prática baseada em evidências levando-o a uma tomada de decisão que promova um tratamento especializado e eficaz a esse paciente (PINHO FM, et al., 2017; COFEN, 2018; OLIVEIRA APBS e PERIPATO LA, 2018).

De uma maneira geral, para avaliar todos os aspectos que se fazem importantes no cuidado dispensado a pacientes vítimas de queimaduras e submetidos à enxertia de pele, o enfermeiro constitui e cumpre papel fundamental. Seu raciocínio clínico e pensamento crítico lhe permitem ampla atuação e domínio sobre as necessidades do paciente. De igual modo, o uso da linguagem padronizada em enfermagem, ou seja, como explicitado neste caso, o diagnóstico de enfermagem, objetiva a correta estratégia terapêutica e a elaboração de plano de cuidado efetivo, o que traduz o pensamento clínico e estratégico e direciona os cuidados de enfermagem (ZIMMERMANN KCG, et al., 2018).

Diversos são os desfechos e consequências negativas associados às queimaduras. Dentre eles, hipovolemia, hipotensão, taquicardia, choque e risco de infecção, com posterior danos aos sistemas respiratório, imunológico e cardiovascular, prejuízos à função renal e mortalidade. Além das complicações 
orgânicas, pode haver repercussões psicológicas e sociais, relacionadas a distúrbios de autoimagem (MOLA $\mathrm{R}$, et al., 2018). Visando minimizar tais complicações, ressalta-se a importância do acompanhamento em ambulatório de queimaduras após a alta hospitalar.

Os cuidados de enfermagem a paciente deste estudo de caso visavam, sobretudo, a promoção e recuperação da integridade da pele, prevenção do agravamento da lesão previamente apresentada, cuidados tanto com área enxertada quanto com a área doadora e auxiliar a paciente no seu processo de enfrentamento. Sendo assim, o enfermeiro exerce um papel fundamental no processo de cicatrização da ferida, prevenção da infecção, que é uma das causas de morte entre os pacientes queimados, pois é o enfermeiro que é protagonista no processo de cuidar.

\section{REFERÊNCIAS}

1. ALVES LM, et al. Agentes físicos na integração de enxertos de pele. Rev. Ciênc. Méd, 2009; 18(4): 201-208.

2. BISINOTTO FMB, et al. Burns related to electrosurgery-Report of two cases. Brazilian Journal of Anesthesiology (English Edition), 2017; 67(5): 527-534.

3. BORGES FS. Modalidades terapêuticas nas disfunções estéticas. 2a ed. São Paulo: Phorte; 2010. CARVALHO NS, et al. Protocolo Brasileiro para Infecções Sexualmente Transmissíveis 2020: infecção pelo papilomavírus humano (HPV). Epidemiologia e Serviços de Saúde, 2021; 30(1): 1-10.

4. CONSELHO FEDERAL DE ENFERMAGEM (COFEN). Resolução no 358, de 15 de outubro de 2009. Dispõe sobre a Sistematização da Assistência de Enfermagem e a implementação do Processo de Enfermagem. Brasil, 2009. Disponível em: http://www.cofen.gov.br/resoluocofen-3582009_4384.html. Acessado em: 09 de abril de 2021.

5. CONSELHO FEDERAK DE ENFERMAGEM (COFEN). Resolução COFEN no 0567/2018: Regulamento da atuação da Equipe de Enfermagem no cuidado aos pacientes com feridas. Brasil, 2018. Disponível em: http://www.cofen.gov.br/wp-content/uploads/2018/02/ANEXO-RESOLU\%C3\%87\%C3\%830-567-2018.pdf. Acessado em: 09 de abril de 2021.

6. CHAVES SCS, et al. Ações da enfermagem para reduzir os riscos de infecção em grande queimado no CTI. Revista Brasileira de Queimaduras, 2013; 12(3): 140-144.

7. GARCIA-ESPINOZA JA, et al. Burns: definition, classification, pathophysiology and initial approach. Gen Med (Los Angeles), 2017; 5(5).

8. GOUVÊA PDP, et al. Assistência de enfermagem ao paciente com grandes queimaduras em um hospital público no interior sul da Amazônia ocidental. Revista Eletrônica Acervo Saúde, 2020; 47(47): e2797-e2797.

9. HERDMAN H, et al. Nursing Diagnoses Definitions and Classification. [eletronic resource] / [NANDA International]; $12^{\mathrm{a}}$ edition, 2021-2023; 1187p.

10. MEHTA SP, et al. Operating Room FiresA Closed Claims Analysis. Anesthesiology: The Journal of the American Society of Anesthesiologists, 2013; 118(5): 1133-1139.

11. MELO UG, et al. Diagnósticos de enfermagem no período transoperatório: mapeamento cruzado. Rev. SOBECC, $2019 ; 24(4): 193-199$.

12. MINISTÉRIO DA SAÚDE. Secretaria de Vigilância em Saúde. Departamento de Doenças de Condições Crônicas e Infecções Sexualmente Transmissíveis. Protocolo Clínico e Diretrizes Terapêuticas para Atenção Integral às Pessoas com Infecções Sexualmente Transmissíveis (IST). Brasil, 2020 Disponível em: http://www.aids.gov.br/ptbr/pub/2015/protocolo-clinico-e-diretrizes-terapeuticas-para-atencao-integral-pessoas-com-infeccoes. Acessado em: 09 de abril de 2021.

13. MOLA R, et al. Características e complicações associadas às queimaduras de pacientes em unidade de queimados. Rev Bras Queimaduras, 2018; 17(1): 8-13.

14. NUNES RS, LOPES KKM. Curativos em queimaduras de terceiro grau. Revista Eletrônica da Faculdade de Ceres, 2018; 7(1): 56-68.

15. OLIVEIRA APBS, PERIPATO LA. A cobertura ideal para tratamento em paciente queimado: uma revisão integrativa da literatura. Rev Bras Queimaduras, 2017; 16(3): 188-93.

16. PERIPATO APBSO, et al. A cobertura ideal para tratamento em paciente queimado: uma revisão integrativa da literatura. Revista Brasileira de Queimaduras, 2017; 16(3): 188-193.

17. PINHO FM, et al. Cuidado de enfermagem ao paciente queimado adulto: uma revisão integrativa. Revista Brasileira de Queimaduras, 2017; 16(3): 181-187.

18. SAAVEDRA PAE, et al. Burns in the Brazilian Unified Health System: a review of hospitalization from 2008 to 2017 . Int J Burn Trauma, 2019; 9 (5): 88-98.

19. SARMENTO BS, et al. Cuidados de Enfermagem ao paciente queimado. 1. ed. rev. Porto Alegre: Moriá, 2018.200 p.

20. SECUNDO CO, et al. Protocolo de cuidados de enfermagem ao paciente queimado na emergência: Revisão integrativa da literatura. Rev Bras Queimaduras, 2019; 18(1): 39-46. STOJKOVSKA J, et al. Comparative in vivo evaluation of novel formulations based on alginate and silver nanoparticles for wound treatments. Journal of biomaterials applications, 2018; 32(9): 1197-1211.TIAN H, et al. Epidemiologic and clinical characteristics of severe burn patients: results of a retrospective multicenter study in China, 2011-2015. Burns \& trauma, 2018; 6(14): 1-11.

21. ÜNAL S, et al. Análise da perda do enxerto de pele por infecção: perda do enxerto relacionada à infecção. Anais de cirurgia plástica, 2005; 55(1): 102-106. ZIMMERMANN KCG, et al. Competências De Enfermagem Para A Prevenção De Necrose E Retração Em Queimaduras. Inova Saúde, 2018; 7(1): 40-59. 